\title{
CAPITULO 9 \\ METODOLOGIAS PARTICIPATIVAS \\ COMO INSTRUMENTO DE GESTÃO \\ TERRITORIAL: EXPERIÊNCIA NO BAIRRO SÃO FRANCISCO, CRICIÚMA - SC
}

DOI: http://dx.doi.org/10.18616/pgt09

Júlia Morona de Campos Kamila Lupin Leandro Nunes Mário Ricardo Guadagnin Yasmine de Moura da Cunha ఏll 


\section{GESTÃO TERRITORIAL NO CONTEXTO URBANO}

A expansão urbana traz consigo fortes impactos ambientais, ainda mais preocupantes quando ocorrem de forma desordenada e sem o devido planejamento. Ocupação em áreas de risco, degradação de recursos hídricos, disposição inadequada de resíduos sólidos e infraestrutura urbana precária são exemplos dos resultados negativos da falta de planejamento ambiental urbano.

Nesse contexto, a gestão territorial se faz necessária para a construção de ambientes sustentáveis, do ponto de vista social, econômico e ambiental. O planejamento e a gestão territorial são mais eficientes e equitativos quando contam com a participação cidadã.

O modelo gerencial das cidades é, habitualmente, uma busca de interesses político-partidários que não atendem às necessidades do coletivo. A organização e mobilização social promovida nos bairros é a forma mais eficiente para a participação política efetiva dos cidadãos na gestão territorial da sua comunidade.

\section{ORGANIZAÇÃO SOCIAL E PARTICIPAC̣ÃO POLÍTICA}

A responsabilidade do planejamento ambiental urbano é frequentemente atribuída aos poderes executivo e legislativo. No entanto, a participação social no processo de gestão territorial e planejamento urbano é a forma mais eficiente de garantir o direito à cidade para todos (NOGUEIRA, 2005).

Os fatos noticiados diariamente que envolvem corrupção, má administração pública e desvio de recursos públicos - em escalas municipal, estadual e federal - têm desmotivado e desesperançado a participação política da sociedade. $O$ descaso com a população, reforçado pela impunidade, provoca uma imensa insatisfação política e, ao invés de encorajar a mudança, inibe cada vez mais o exercício da cidadania. 
A apatia coletiva e o descrédito com a política dos partidos e dos governos, da situação ou da oposição, não é apenas "um grave sintoma para a saúde da democracia". É uma manifestação agônica dos órfãos de utopias, dos que nada têm a perder, dos excluídos de direitos, saber e poder, dos sonhadores de liberdade e de justiça, dos que - relegados a condição de pré-cidadão, ou no máximo, exercendo uma cidadania minguada, tutelada ou regulada - já não têm esperança e, menos ainda, confiança de que algo vá mudar para eles ou na vida deles, depois das eleições (TEIXEIRA, 2004, p. 96).

A participação social, contudo, não se restringe ao "voto consciente". Para Milton Santos, o eleitor que não atua de forma ativa e dinâmica na sua comunidade, e cujo papel se encerra no voto, não é cidadão. Do contrário, "o cidadão é multidimensional" e "cada dimensão se articula com as demais na procura de um sentido para a vida." (SANTOS, 2014, p. 56).

O cidadão politizado exerce sua cidadania e seus direitos, e não permite ao eleito que se exima das suas responsabilidades, no exercício do poder, para com a sociedade como um todo (TEIXEIRA, 2004). Aqueles que não exercem a cidadania tornam-se alienados e sentem-se profundamente incapazes de mudar a condição da sua comunidade, município e nação.

O descrédito com a política, discutido por Teixeira (2004), precisa tornar-se o combustível para a atuação efetiva da sociedade nos processos de gestão e planejamento urbano.

Para que a mudança governamental ocorra, é necessário que a política deixe de ser vista como oportunidade de beneficiamento de poucos em detrimento do coletivo, e passe a ser tratada como "uma arte e um caminho para educar a cidadania e mobilizar a sociedade", pois "só a partir dela poderemos mudar as condições de vida abaixo da média do conhecimento ou da linha da pobreza" (TEIXEIRA, 2004, p. 26). 
A organização social é o principal instrumento para a participação cidadã. Castro (2009, p. 139) defende que, "quanto mais organizada a sociedade, maior a sua possibilidade de influenciar a agenda política através da representação"

Os bairros e suas associações são o espaço mais fértil para o estabelecimento do diálogo e cooperação social. Para Freire (2003, p. 12), "aprender e ensinar fazem parte da existência humana, histórica e social". Tendo em vista a oportunidade de atuação nos bairros, o projeto de extensão "Diálogos Urbanos no Território Paulo Freire: políticas públicas e construção do direito à cidade" buscou unir a pedagogia freiriana com o empoderamento de lideranças comunitárias.

Utilizando metodologias participativas, a fim de promover o ensino horizontal, em que o educador aprende enquanto ensina, e o educando ensina enquanto aprende, buscou-se a autonomia cidadã.

\section{METODOLOGIAS PARTICIPATIVAS}

As metodologias participativas se estabelecem como pano de fundo central no trabalho desenvolvido pelo Projeto de Extensão "Diálogos Urbanos". A mudança social na comunidade deve ser desenvolvida através da participação coletiva, em que o "grupo de interesse" deve ser construído através do estabelecimento de objetivos comuns aos moradores do bairro.

A proposta de educação popular construída pelo "Projeto Diálogos Urbanos" junto à comunidade se pauta pela participação política do grupo de interesse e autonomia do grupo de representação comunitária nos processos decisórios. Contudo, é de extrema importância considerar a centralidade do diagnóstico participativo com o propósito de a comunidade reconhecer as próprias demandas antes de planejar e agir.

As reuniões de moradores de uma comunidade, na perspectiva das "Metodologias Participativas", privilegiam as experiências de diálogo, as quais contribuem para a criação de novos sentidos resultando no 
empoderamento dos sujeitos envolvidos. Objetiva-se a cidadania e a transformação social, no entanto as reuniões devem se caracterizar como "lugar" de emancipação dos sujeitos (QUEIROZ; COUTO, 2015).

Para exemplificar o processo político estabelecido através das metodologias participativas, pode-se pensar a partir da perspectiva de Hannah Arendt, a qual estabelece a política como "ação". A ação do homem no mundo é política, e, portanto, nós nos "construímos" no diálogo com o outro. Dessa forma, a política é constituída na pluralidade. "Somos muitos, mas somos todos diferentes" e a diferença forma o espaço político através da diversidade.

A ação, única atividade que se exerce diretamente entre os homens sem a mediação das coisas ou da matéria, corresponde à condição humana da pluralidade, ao fato de que homens, e não o homem, vivem na Terra e habitam o mundo. Todos os aspectos da condição humana têm alguma relação com a política; mas esta pluralidade é especificamente a condição - não apenas a conditio sine qua non, mas a conditio per quam - de toda a política (ARENDT, 2007, p. 2015).

O processo político participativo gera aprendizagem em ambas as partes, nos facilitadores e na comunidade onde o trabalho é desenvolvido. Uma vez que ocorra uma estagnação no processo de aprendizagem, deve ser realizada uma discussão e reflexão sobre os objetivos da atividade proposta, pois toda a "construção" deve ser participativa.

O processo de aprendizagem é gerado pela interação, sentimentos, atitudes, crenças, costumes e ações dos sujeitos. As metodologias ativas estimulam a reflexão sobre as atividades realizadas gerando um tipo de reorientação de posturas, atos e opiniões a partir de uma visão crítica da realidade (ROCHA; BEVILACQUA; BARLETTO, 2015).

$A$ atitude crítica é muito importante para o facilitador que utiliza metodologias participativas, pois a conduta atenta do facilitador fará 
com que seja evitado que se construa pontos de vistas fatalistas sobre a realidade a qual se apresenta. $O$ facilitador de grupo deve estar vigiante quando houver a iminência de posturas fatalistas advindas dos membros da comunidade, pois essas irão impedir a transformação social. É importante conhecer a história e as condições socioculturais e econômicas da comunidade para que seja possibilitado que se identifique a natureza do pensamento fatalista comunitário.

Segundo Ansara e Dantas (2010, p. 97), “O indivíduo que nasce na periferia das cidades latino-americanas aprende cotidianamente qual é o seu lugar social e que seus esforços provavelmente não produziram transformações efetivas na sociedade, marcada pela exploração e opressão". A ideologia fatalista é reforçada pela realidade social e pela transmissão através de organizações institucionais, bem como processo de institucionalização. Tal fenômeno ocorre através da educação doméstica, da escola, da igreja e do trabalho (ANSARA; DANTAS, 2010, p. 97).

A subjetivação individual não ocorre isolada, no âmago do sujeito, desvinculada da subjetivação social; pelo contrário, ela se produz em espaços sociais, que abrigam certa história, assim como lugar e interação social (QUEIROZ; COUTO, 2015, p. 175). As ações do Projeto de Extensão Diálogos Urbanos pautaram-se pelas considerações abordadas por Queiroz e Couto (2015) acima, com o intuito de buscar a participação e transformação social utilizando-se das metodologias participativas.

\section{PERCURSO METODOLÓGICO}

O Território Paulo Freire, área de atuação, é um Programa de Extensão da Universidade do Extremo Sul Catarinense (UNESC) com o objetivo de desenvolver projetos de extensão que ampliem a capacidade de autonomia das comunidades envolvidas. Fazem parte do Território Paulo Freire treze bairros vizinhos do município de Criciúma: São Defende, Santo André, São Sebastião, Nova Esperança, Progresso, Vila Manaus, Cidade 
Mineira Nova, Cidade Mineira Velha, Vila Belmiro, Jardim União, Santa Luzia, Imperatriz e São Francisco.

O projeto de extensão "Diálogos Urbanos no Território Paulo Freire: políticas públicas e construção do direito à cidade" propõe suscitar a autonomia em lideranças comunitárias e promover a participação cidadã. Integrando docentes e discentes de áreas multidisciplinares - psicologia, geografia e engenharia ambiental e sanitária -, a proposta do projeto é propiciar aos participantes instrumentos para a busca de soluções para os problemas locais.

Em fevereiro de 2016, o projeto iniciou com o planejamento de atividades e discussões sobre as temáticas relacionadas. Em agosto, a equipe realizou uma saída a campo nas comunidades do Território Paulo Freire a fim de identificar possíveis entidades parceiras e comunidades que demonstrassem interesse pelo projeto. Uma das instituições visitadas, a Escola Municipal Oswaldo Hülse, no bairro São Francisco (Figura 1), mostrou-se aberta ao projeto. Na visita, realizou-se uma roda de conversa com alguns funcionários da escola e moradores do bairro e foi possível perceber o interesse local pela participação no projeto. 
Figura 1 - Perímetro do bairro São Francisco, Criciúma - SC

\section{Piálogos Urbanos no Território Paulo Freire unesc Politicas Públicas e Construçäo do Direito à Cidade}

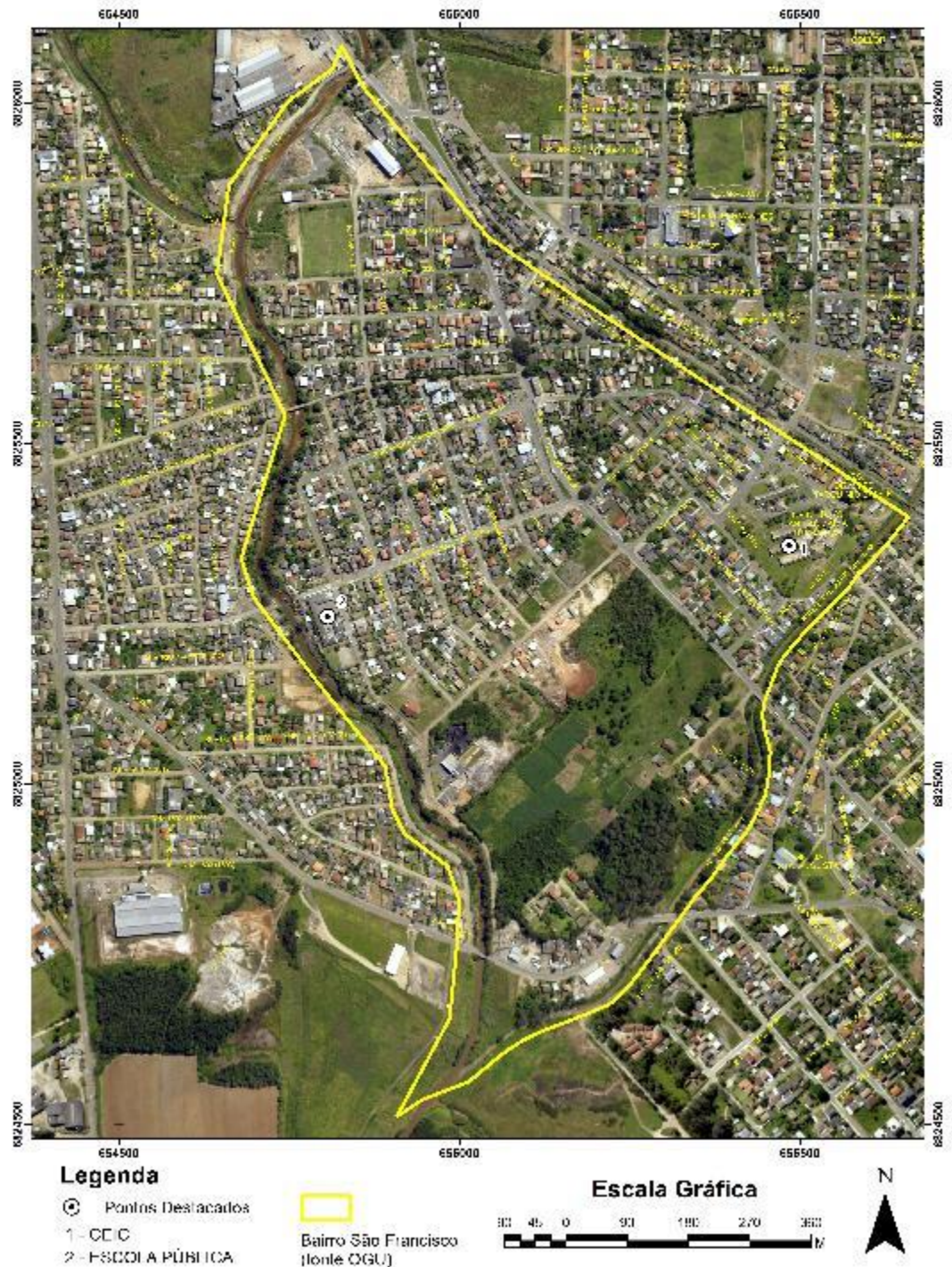

Fonte: UNESC, 2017. 


\section{METODOLOGIAS PARTICIPATIVAS APLICADAS}

Sediadas na Escola Oswaldo Hülse, as reuniões com a comunidade iniciaram também em agosto de 2016. A partir da reunião inicial, outros moradores foram convidados pela equipe por indicação dos funcionários.

Os encontros foram planejados com três objetivos iniciais: conhecimento e integração do grupo, conhecimento do bairro e identificação de vulnerabilidades, definição de metas e planejamento de ações. Para cada objetivo, foram escolhidas metodologias participativas específicas (Figura 2).

Figura 2 - Metodologias participativas aplicadas nos encontros

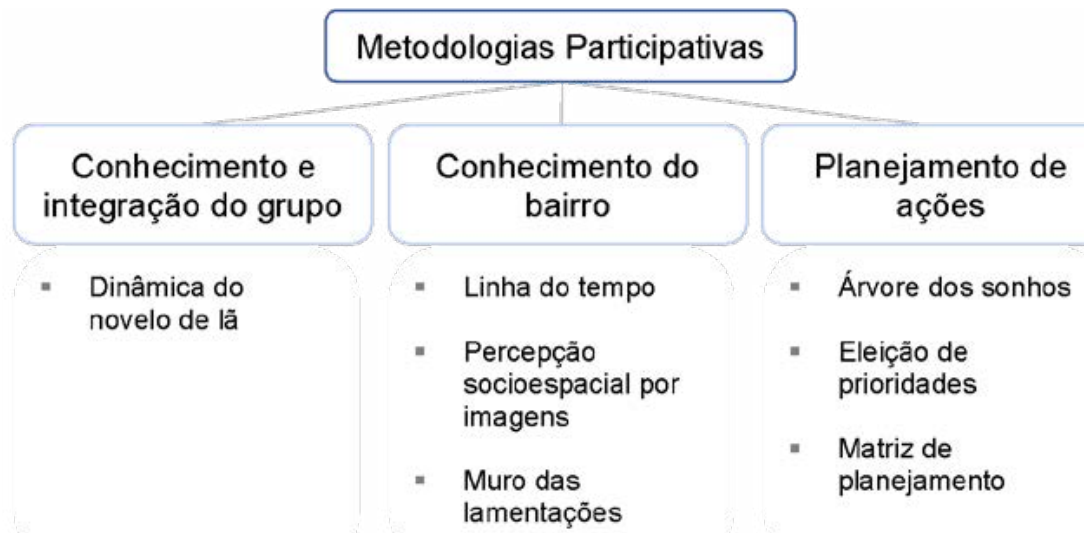

Fonte: dos autores, 2017.

\section{DINÂMICA DO NOVELO DE LÃ}

No primeiro encontro, utilizou-se a técnica do novelo de lã, também conhecida como "teia de aranha". O objetivo dessa técnica é a integração dos participantes (Figura 3). 
Para a prática, é necessário que os participantes estejam dispostos em um círculo. A dinâmica iniciou com um participante segurando a ponta do novelo e apresentando-se ao grupo; após a apresentação, o participante jogou o novelo para outro participante da roda, que se apresentou, manteve a linha segurada e jogou o novelo para outro participante. 0 processo se repetiu até que todos se apresentaram.

Figura 3 - Dinâmica do novelo de lã

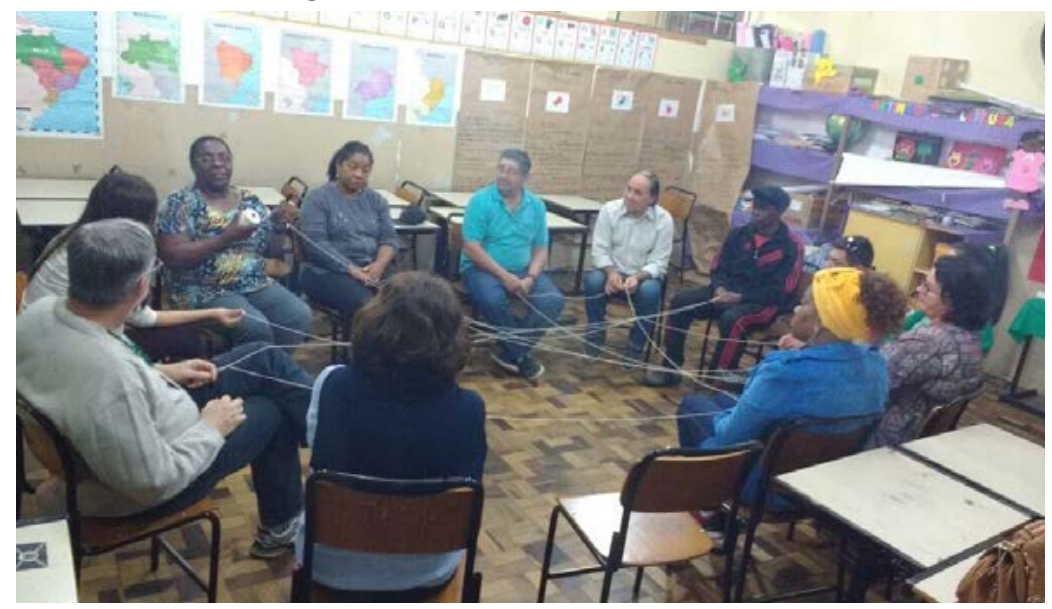

Fonte: dos autores, 2017.

\section{LINHA DO TEMPO POSITIVA E NEGATIVA}

Nessa técnica, os participantes foram convidados a relembrar os eventos significativos que ocorreram na comunidade ao longo do tempo. Para essa atividade, foram necessárias canetas para todos os participantes, papel pardo com o traçado da linha temporal e tarjetas de duas cores diferentes (brancas e amarelas) para a descrição de eventos positivos e negativos.

O mediador distribuiu as canetas e tarjetas para os participantes e os orientou a escrever os eventos positivos nas tarjetas de cor branca e 
os eventos negativos nas tarjetas de cor amarela. Após um tempo para a descrição dos eventos, o mediador convidou cada participante a socializar com o grupo os eventos dos quais se recordou (Figura 4).

As tarjetas foram situadas na linha temporal de forma que eventos positivos ficassem acima da linha e eventos negativos ficassem abaixo da linha.

Figura 4 - Linha do tempo positiva/negativa montada com a participação da comunidade

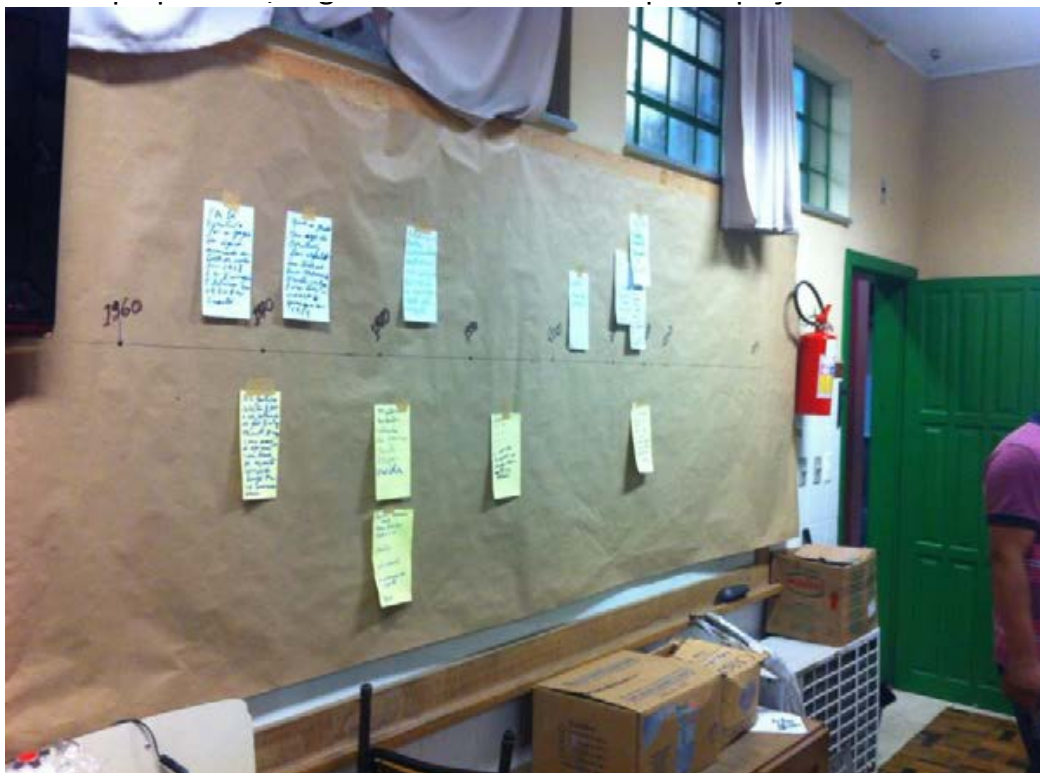

Fonte: dos autores, 2017

\section{PERCEPÇÃO SOCIOESPACIAL POR IMAGENS}

Nessa atividade, os participantes observaram o território através da imagem aérea no mapa do bairro. A equipe distribuiu um mapa do bairro impresso para cada participante, e foi solicitado que identificassem as suas residências e pontos de referência. 
Além disso, foram apontados problemas ambientais e de infraestrutura. Para uma melhor compreensão e análise, a equipe propôs aos moradores que fotografassem os problemas citados e compartilhassem as imagens no encontro seguinte.

Os moradores fotografaram e trouxeram as fotos em meio digital e impresso para compartilhar com o grupo (Figura 5).

Figura 5 - Imagens trazidas pelos moradores reproduzindo e expondo problemas no bairro
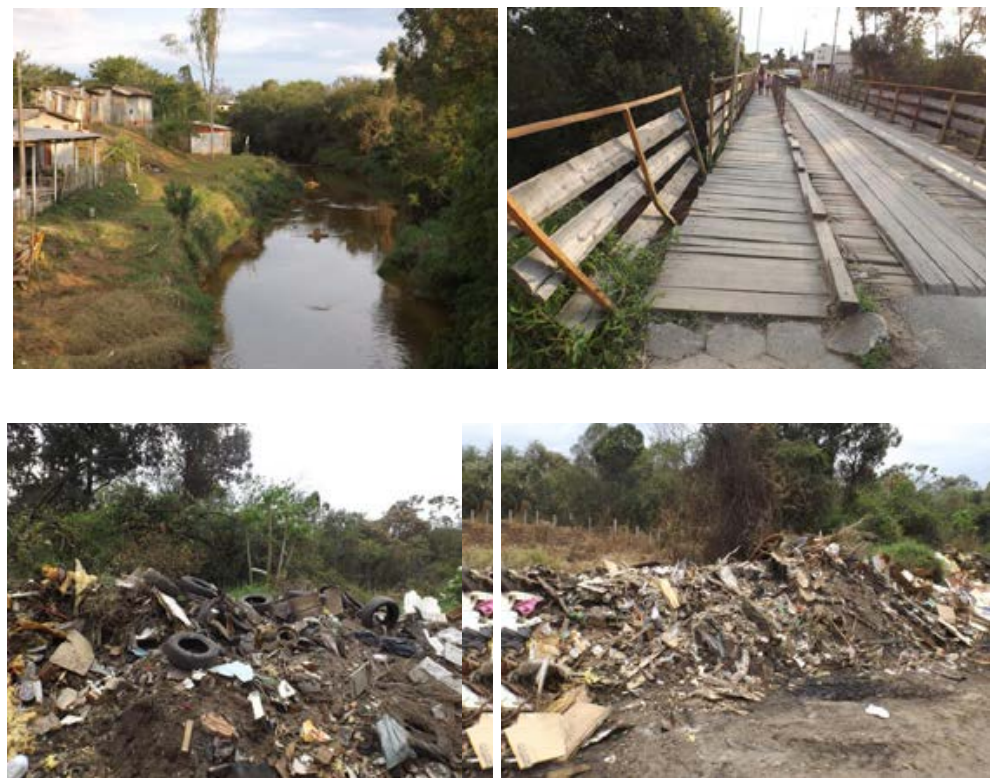

Fonte: dos autores, 2017

\section{MURO DAS LAMENTAÇÕES}

Essa técnica foi utilizada para a percepção dos problemas existentes no bairro. Para a atividade, foram necessários papel pardo com o desenho de um muro de tijolos, canetas para todos os participantes, tarjetas no tamanho dos tijolos (Figura 6). 
Os participantes receberam as tarjetas I e canetas e foram convidados a escreverem os problemas existentes no bairro nos tijolinhos. Após um tempo para os participantes escreverem os problemas, a equipe convidou cada participante a explicar os problemas que relatou. Os tijolos foram fixados no muro, agrupados pela semelhança temática.

Figura 6 - Muro das lamentações com problemas elencados conforme percepção da comunidade

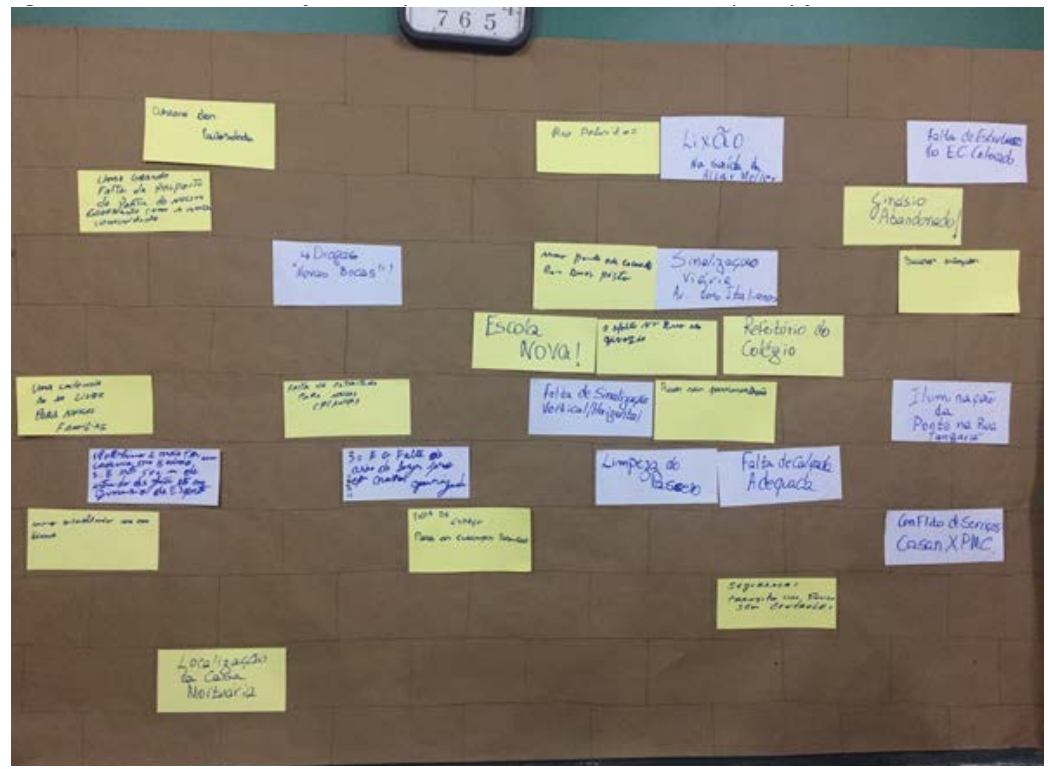

Fonte: dos autores, 2017

\section{ÁRVORE DOS SONHOS}

Relembrando os problemas discutidos nos encontros anteriores, a técnica da árvore dos sonhos convidou os moradores a pensarem nos sonhos que desejavam para o bairro. Para a atividade, foram utilizadas uma árvore desenhada em papel pardo, canetas por todos os partici- 
pantes, folhas de papel em formato de folhas de árvore e adesivos em formato de bolinha.

A equipe distribuiu as folhas da árvore e canetas para os participantes e pediu para que escrevessem o que desejavam para o bairro. As folhas foram fixadas na copa da árvore, agrupadas por semelhança temática.

Depois de fixar todos os sonhos, foram distribuídos seis adesivos para cada participante. A equipe solicitou aos moradores que elegessem os sonhos que eram prioridades para o bairro (Figura 7). A votação foi realizada com os adesivos. Cada participante distribuiu os adesivos nas folhas de forma que o sonho considerado mais prioritário recebeu três adesivos; o sonho considerado como segundo grau de prioridade recebeu dois adesivos; e o sonho considerado como terceiro grau de prioridade, um adesivo.

Figura 7 - Momento de escolha e eleição das prioridades na árvore dos sonhos

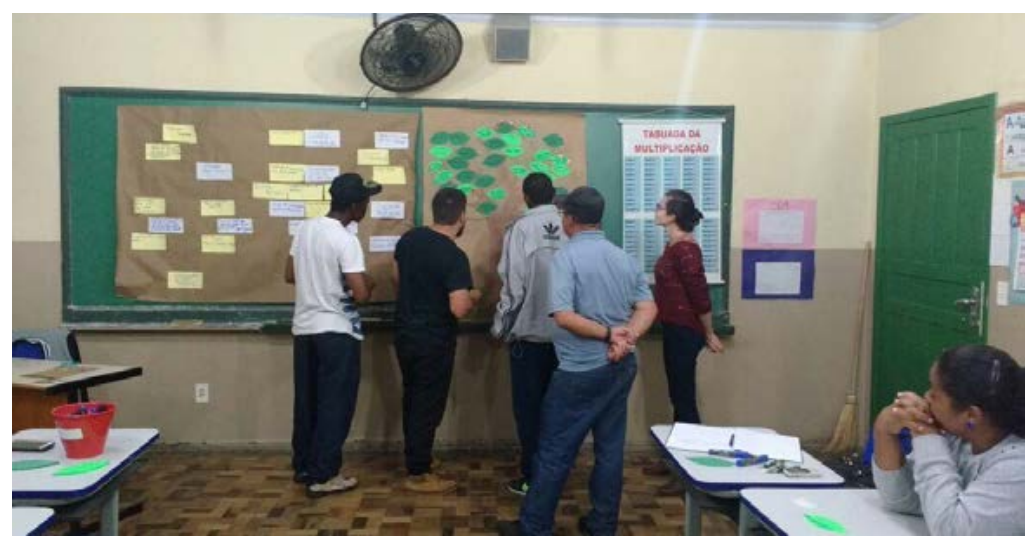

Fonte: dos autores, 2017

\section{MATRIZ DE PLANEJAMENTO DE AÇÕES}

A última técnica utilizada foi inspirada na Agenda 21, proposta na Conferência das Nações Unidas sobre Meio Ambiente e 
Desenvolvimento de 1992 no Rio de Janeiro. A equipe elaborou uma matriz para facilitar o planejamento de ações e delegação de tarefas. Foram planejadas ações para o alcance das metas, priorizando as que obtiveram maior número de votos na eleição de prioridades.

Para cada ação, foram definidos objetivos, os responsáveis por realizá-la, o prazo para a conclusão e os indicadores de resultados (Figura 8).

Figura 8 - Matriz de planejamento das ações elaborada pela equipe

\section{Agenda 21 - Bairro São Francisco}

Sonhos Ações Objetivo/meta Responsáveis Prazo Indicadores de resultado

Fonte: dos autores, 2017

Figura 9 - Construção participativa da matriz de planejamento

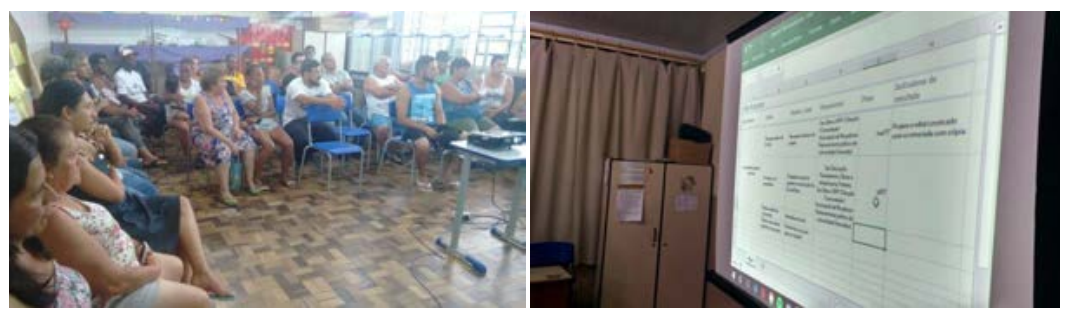

Fonte: dos autores, 2017

\section{RESULTADOS E DISCUSSÃO}

A comunidade do bairro São Francisco atingiu, através das metodologias participativas e da participação e integração desenvolvida pela comunidade ao longo dos encontros, um novo nível de empoderamento e autonomia comunitária e social. Porém, o que propiciou que o empoderamento social e comunitário fosse atingido foram os processos que o 
antecederam. Esses processos se deram a partir das rodas de conversa, dos encontros, dinâmicas e oficinas realizadas.

Os primeiros encontros foram destinados ao conhecimento e integração do grupo, através da dinâmica do novelo de lã. Essa dinâmica propiciou ao grupo maior integralidade e empatia, que foram essenciais para a união dele. A afinidade que começou a construir-se nesse primeiro momento contribuiu para a eficácia da busca de interesses em comum, que nesse caso é o bairro, potencializando a participação coletiva, pois um grupo unido e empático torna-se motivado.

A linha do tempo, juntamente com a percepção socioespacial por imagens e o muro das lamentações, privilegiou experiências de diálogos e trocas de perspectivas sobre o bairro São Francisco. E, a partir dessas discussões, foi construída a árvore dos sonhos, criando novos sentidos e perspectivas de ação do coletivo.

A matriz de planejamento auxiliou a organização das ações dentro da comunidade, que produziram transformações efetivas na realidade daquele grupo. A utilização dessa técnica, contudo, não foi eficiente em sua plenitude. Percebeu-se a falta de apropriação dessa ferramenta pelos moradores. No uso dessa técnica, é necessário promover mais envolvimento dos moradores na elaboração da matriz, a fim de estimular a apropriação efetiva e continuidade.

As oficinas foram responsáveis por contribuir como arcabouço teórico para o grupo, tornando-o mais consciente e preparado para argumentar sobre esses assuntos. As oficinas instigaram no grupo discussões, reflexões e pensamentos críticos e inquietos, não mais conformados com a realidade.

\section{CONSIDERAÇÕES FINAIS}

A experiência relatada ressalta o potencial de aplicação das metodologias participativas em ambiente comunitário. $\mathrm{O}$ uso das metodologias participativas mostrou-se muito eficaz na coesão e união do grupo. 
Cada oficina realizada ampliou o conhecimento da equipe do Projeto Diálogos Urbanos sobre o bairro, e do bairro sobre si mesmo.

As metodologias participativas proporcionaram uma participação ativa, de forma que a análise crítica do ambiente fosse feita pelos próprios moradores, sendo a equipe do projeto de extensão agente mediador do processo. Outro ponto positivo para as metodologias participativas é a capacidade de integração do grupo, pois promove mais diálogo, com troca de ideias e saberes.

A integração dos membros do grupo foi o ingrediente mais importante para a busca de soluções para as vulnerabilidades identificadas no território. A coesão grupal torna o grupo mais forte e os integrantes cooperam muito mais entre si, possibilitando bons resultados.

\section{REFERÊNCIAS}

ARENDT, Hannah. A condição humana. 10. ed. Rio de Janeiro: Forense Universitária, 2007.

ANSARA, Soraia; DANTAS, Bruna Suruagy do Amaral. Intervenções psicossociais na comunidade: desafios e práticas. Psicologia Social, Florianópolis, v. 22, n. 1, p. 95-103, abr. 2010.

CASTRO, I. E. Geografia e Política: território, escalas de ação e instituições. 2. ed. Rio de Janeiro: Bertrand Brasil, 2009.

FREIRE, P. Política e Educação: ensaios. São Paulo: Cortez, 2003.

NOGUEIRA, A. C. R. M. Amanda da Conceição Rocha de Melo. Planejamento e gestão territorial: uma análise sobre as estratégias de e ambiental do município de Maricá/RJ. 2015. 166 f. Trabalho de Conclusão de Curso (Especialização em Engenharia Urbana) - Universidade Federal do Rio de 
Janeiro, Escola Politécnica, Rio de Janeiro. Disponível em: <http://www. peu.poli.ufrj.br/arquivos/Monografias/Amanda_Nogueira.pdf> Acesso em: 19 ago. 2017.

QUEIROZ, Adriana Gonçalves; COUTO, Ana Cláudia Porfírio. Metodologia participativa, subjetividade individual e social: facilitação de reuniões de moradores em Residências Terapêuticas. Pesquisa e práticas sociais, São João Del-Rei, v. 10, n.1, p. 171-178, jan./jun., 2015.

ROCHA, Natália Hosana Nunes; BEVILACQUA, Paula Dias; BARLETTO, Marisa. Metodologias participativas e educação permanente na formação de agentes comunitários/as de saúde. Trabalho, Educação e Saúde, Rio de Janeiro, v. 13 n. 3, p. 597-615, set./dez. 2015.

SANTOS, M. O Espaço do cidadão. 7. ed. São Paulo: Editora da Universidade de São Paulo: 2014.

TEIXEIRA, J. P. A utilidade dos políticos. Florianópolis: Cidade Futura, 2004. 